\title{
Primary research \\ C-type natriuretic peptide concentrations in the plasma and cerebrospinal fluid of patients with subarachnoid hemorrhage
}

Kazumi Ikeda*, Toshiaki Ikeda*, Toshiaki Onizuka*, Hiroo Terashi* and Tadaharu Fukuda ${ }^{\star}$

*Division of Critical Care and Emergency Medicine, Hachioji Medical Center of Tokyo Medical University, Tokyo, Japan

${ }^{+}$Department of Neurosurgery, Hachioji Medical Center of Tokyo Medical University, Tokyo, Japan

Correspondence: Kazumi lkeda, MD, Division of Critical Care and Emergency Medicine, Hachioji Medical Center of Tokyo Medical University, 1163 Tatemachi, Hachioji, Tokyo 193-0944, Japan. Tel: +81 42665 5611; fax: +81 42665 1796; e-mail: hmc@tokyo-med.ac.jp

Received: 6 January 2000

Revisions requested: 20 September 2000

Revisions received: 26 October 2000

Accepted: 17 November 2000

Published: 22 December 2000
Critical Care 2001, 5:37-40

(C) 2001 Ikeda et al, licensee BioMed Central Ltd (Print ISSN 1364-8535; Online ISSN 1466-609X)

\begin{abstract}
Background: Cerebral vasospasm is a poor resulting outcome of a ruptured cerebral aneurysm; to clarify the mechanism of vasospasm it is important to improve this outcome. C-type natriuretic peptide $(\mathrm{CNP})$ is present in the brain as a cerebral vasodilator; it is also an endothelium-derived relaxing factor produced via cGMP. We speculated that CNP might be an inhibitor of cerebral vasospasm after subarachnoid hemorrhage (SAH).
\end{abstract}

Methods: To clarify the role of CNP in cerebral vasospasm after SAH, we conducted 1 week monitoring of CNP concentrations in the plasma and cerebrospinal fluid (CSF) of 26 patients who had undergone clipping within 24 hours of the occurrence of $\mathrm{SAH}$, and divided them into group A (positive for angiographic spasm) and group B (negative for angiographic spasm). We also examined CNP concentrations in the CSF of patients who were receiving spinal anesthesia for small orthopedic operations, as reference patients.

Results: The CNP concentration in the CSF on day 1 was higher than in the reference patients and decreased in both test groups, but we did not observe any significant difference between the groups. CNP concentrations in the plasma did not change in either group.

Conclusions: CNP concentrations in the CSF were high in the acute phase after SAH, whereas plasma CNP concentrations remained constant. However, our findings did not support our hypothesis because we did not find any relationship between vasospasm and changes in CNP concentrations in the CSF.

Keywords: cerebral vasospasm, C-type natriuretic peptide, subarachnoid hemorrhage

\section{Introduction}

Cerebral vasospasms after subarachnoid hemorrhage (SAH) have been studied from various aspects, which is a poor outcome resulting from SAH with a ruptured cerebral aneurysm. For example, it has been reported that symptomatic patients had higher cerebrospinal fluid (CSF) levels of interleukin-6 and interleukin-8 than asymptomatic patients [1,2], and nitrites/nitrate increased in the CSF in SAH patients $[3,4]$.

Previous studies showed that C-type natriuretic peptide (CNP) is the primary active natriuretic peptide in the

$\mathrm{ANP}=$ atrial natriuretic peptide; $\mathrm{BNP}=$ brain natriuretic peptide; $\mathrm{CNP}=\mathrm{C}$-type natriuretic peptide; $\mathrm{CSF}=$ cerebrospinal fluid; $\mathrm{NO}=$ nitric oxide; $\mathrm{SAH}=$ subarachnoid hemorrhage. 
Table 1

\begin{tabular}{|c|c|c|c|c|c|c|}
\hline No. & Age & Sex & WFNS & Fisher & Location of AN & Outcome \\
\hline 1 & 46 & $\mathrm{~F}$ & 4 & 4 & R-MCA & VS \\
\hline 2 & 43 & M & 2 & 3 & L-AcomA & VS \\
\hline 3 & 47 & $\mathrm{~F}$ & 2 & 2 & L-AcomA & GR \\
\hline 4 & 51 & M & 2 & 3 & R-AcomA & VS \\
\hline 5 & 60 & $\mathrm{~F}$ & 2 & 4 & L-AcomA & GR \\
\hline 6 & 50 & $\mathrm{~F}$ & 2 & 4 & L-AcomA & $\mathrm{D}$ \\
\hline 7 & 48 & $\mathrm{~F}$ & 2 & 2 & L-MCA & GR \\
\hline 8 & 73 & M & 3 & 3 & R-ICPC & $\mathrm{D}$ \\
\hline 9 & 67 & $\mathrm{~F}$ & 4 & 4 & L-AcomA & VS \\
\hline 10 & 64 & $\mathrm{~F}$ & 2 & 2 & L-AcomA & GR \\
\hline 11 & 60 & $\mathrm{~F}$ & 4 & 3 & R-MCA & VS \\
\hline 12 & 63 & $\mathrm{~F}$ & 5 & 4 & L-MCA & GR \\
\hline 13 & 54 & M & 4 & 3 & L-ICPC & GR \\
\hline 14 & 64 & $\mathrm{~F}$ & 2 & 3 & R-MCA & VS \\
\hline 15 & 64 & M & 3 & 3 & L-AcomA & $\mathrm{D}$ \\
\hline 16 & 71 & $\mathrm{~F}$ & 4 & 4 & R-MCA & GR \\
\hline
\end{tabular}

Outcome was evaluated with the Glasgow Outcome Scale. Mean age $( \pm \mathrm{SD})$ was $53.8 \pm 7.6$ years. AN, aneurysm; AcomA, anterior communicating artery; $\mathrm{D}$, death; ICPC, internal carotid-posterior communicating artery; GR, good recovery; MCA, middle cerebral artery; MD, moderate disability; SD, severe disability; VS, vegetative state; WFNS, World Federation of Neurosurgical Societies SAH grade.

human brain; CNP is also considered to be an endothelium-derived relaxant factor, which acts in the same way as nitric oxide (NO) $[5,6]$. On the basis of these previous findings, we assumed that CNP might have vasodilator effects to inhibit vasospasm after $\mathrm{SAH}$, and conducted the present study to determine the relationship between the changes in CNP with cerebral vasospasm after SAH.

\section{Patients and methods}

This study was approved by an ethical committee of our university, and we obtained informed consent for enrolled patients, including those patients used as a reference.

Twenty-six patients with SAH due to aneurysm rupture were included in the study after aneurysm clipping within 24 hours of onset. Patients with chronic heart failure (history) or renal diseases (a serum creatinine level of more than $5.0 \mathrm{mg} / \mathrm{dl}$ ) were excluded from this study. Postoperative hyperdynamic therapy was given, aiming at a central venous pressure or a mean right atrial pressure of $100-150 \mathrm{mmHg}$, a mean arterial pressure of $100-120 \mathrm{mmHg}$ and a hematocrit of $36-40 \%$ from day 3 . Intravenous nicardipine hydrochloride
Table 2

Characteristics of patients in group B

\begin{tabular}{lcccccc} 
No. & Age & Sex & WFNS & Fisher & Location of AN & Outcome \\
\hline 1 & 64 & F & 3 & 3 & R-ICPC & GR \\
2 & 56 & M & 2 & 2 & L-ICPC & GR \\
3 & 32 & F & 3 & 2 & L-AcomA & GR \\
4 & 50 & F & 2 & 2 & BA & GR \\
5 & 75 & F & 5 & 4 & L-ICPC & D \\
6 & 58 & F & 3 & 4 & L-MCA & GR \\
7 & 67 & M & 3 & 3 & BA & GR \\
8 & 81 & F & 5 & 4 & R-MCA & VS \\
9 & 51 & F & 1 & 2 & L-AcomA & GR \\
10 & 72 & F & 3 & 3 & R-MCA & GR \\
\hline
\end{tabular}

Outcome was evaluated with the Glasgow Outcome Scale. Mean age $( \pm \mathrm{SD})$ was $59.3 \pm 14.6$ years. AN, aneurysm; AcomA, anterior communicating artery; BA, basilar artery; D, death; ICPC, internal carotid-posterior communicating artery; GR, good recovery; MCA, middle cerebral artery; VS, vegetative state; WFNS, World Federation of Neurosurgical Societies SAH grade.

(60-80 mg/day) was given from day 1 , and angiography was undertaken to monitor the occurrence of vasospasms from days 5-7 of hospitalization. An independent neurosurgeon established cerebral vasospasm as graded in the Kasselis classification (moderate and severe were recognized as spasm) [7]. They were divided into group $A$ (positive for angiographic spasm) and group $B$ (negative for angiographic spasm).

We performed angiography several times as required, and classified the patients according to the angiographic findings from days $5-7$.

Table 1 summarizes the characteristics of group $A$ patients. They were $53.8 \pm 7.6$ (mean \pm SD) years of age. Vasospasm was confirmed angiographically in 16 of the 26 patients. Outcomes were evaluated by using the Glasgow Outcome Scale on day 30 of hospitalization. Table 2 summarizes the characteristics of group B. Their age (mean $\pm S D$ ) was $59.3 \pm 14.6$ years.

CNP concentrations in the plasma and CSF were measured on days 1, 3 and 7 of hospitalization. Blood samples were obtained with a radial arterial catheter and were centrifuged at $4^{\circ} \mathrm{C}$. Plasma was separated, frozen immediately and stored at $-20^{\circ} \mathrm{C}$ until analysis. CSF samples were obtained with a cisternal drain or ventricular drain inserted during surgery. After the removal of blood from the sample, the CSF was stored at $-20^{\circ} \mathrm{C}$ until analysis.

CNP immunoactivity was determined with a double antibody radioimmunoassay with RIK 9030 kit (Peninsula Lab- 
oratories Inc, San Carios, CA, USA) [8]. To obtain reference data, $1-2 \mathrm{ml}$ of CSF was sampled from 20 patients who were receiving spinal block anesthesia for small orthopedic operations. CSF sampling from the reference patients was conducted only at surgery.

Data are expressed as means \pm SD. Statistical analysis was performed with an analysis of variance. $P$ values of less than 0.05 were considered statistically significant.

\section{Results}

CNP concentrations in plasma and CSF are presented in Tables 3 and 4. Plasma concentrations are in the normal ranges and did not change significantly within the first week after the onset of SAH. We also did not observe any significant difference between the groups.

The CNP level in the CSF of twelve patients of group A and eight patients of group $B$ was higher on day 1 than the reference data $(13.5 \pm 4.7 \mathrm{pg} / \mathrm{ml})$, but mean levels in both groups were not significantly higher than the reference data. CNP concentrations in the CSF decreased gradually in both groups, but these changes were not significant. We also did not observe any significant difference in the data between the groups.

\section{Discussion}

This preliminary study indicated that CNP in CSF could act as a vasodilator when vasospasms occur in the brain. However, many test patients showed a higher value of CNP in the CSF on day 1 than the reference data, and CNP in the CSF decreased gradually for 1 week, whereas CNP in the plasma did not change. However, this phenomenon was independent of cerebral vasospasms.

CNP is structurally related to atrial natriuretic peptide (ANP) and brain natriuretic peptide (BNP) [9-11]. ANP and BNP are synthesized predominantly in the myocardium, whereas CNP is synthesized in the vascular endothelium. CNP is thought to possess vasodilator effects on both arteries and veins and has been reported to act mainly on the vein by increasing the intracellular cGMP concentration in vascular smooth muscle cells $[12,13]$. Both NO and CNP act as a biological messengers and endogenous vasodilators in several different organs [14]. Suzuki et al showed that $\mathrm{NO}_{x}$ levels in the CSF of SAH patients were markedly higher than the baseline values of healthy subjects and patients with other neurologic diseases, and $\mathrm{NO}_{x}$ increased in patients without vasospasm but not in patients with vasospasm. They assumed that a large amount of NO might be produced by an inducible isoform of $\mathrm{NO}$ synthase (iNOS) after SAH and that this might prevent vasospasm or might have a suppressive effect $[15,16]$. CNP induced dose-dependent vasodilation, but ANP and BNP produced little or no vasodilation; this suggested that CNP causes significant
Table 3

C-type natriuretic peptide (CNP) levels in the plasma

\begin{tabular}{lccc}
\hline & \multicolumn{3}{c}{ CNP level (pg/ml) } \\
\cline { 2 - 4 } & Day 1 & Day 3 & Day 7 \\
\hline Group A (positive for spasm) & $4.6 \pm 0.8$ & $4.5 \pm 1.0$ & $4.2 \pm 0.7$ \\
Group B (negative for spasm) & $5.8 \pm 0.8$ & $5.8 \pm 2.0$ & $6.4 \pm 1.7$
\end{tabular}

The normal level of CNP was less than $4 \mathrm{pg} / \mathrm{ml}$. Figures are

means \pm SD. Day 1 is the day of hospitalization.

Table 4

C-type natriuretic peptide levels in the cerebrospinal fluid

\begin{tabular}{lrcr}
\hline & \multicolumn{3}{c}{ CNP level (pg/ml) } \\
\cline { 2 - 4 } & Day 1 & Day 3 & Day 7 \\
\hline Group A (positive for spasm) & $15.8 \pm 9.6$ & $13.1 \pm 5.6$ & $11.5 \pm 5.4$ \\
Group B (negative for spasm) & $17.0 \pm 5.7$ & $13.7 \pm 3.1$ & $9.1 \pm 2.7$
\end{tabular}

The reference level was $13.5 \pm 4.7 \mathrm{pg} / \mathrm{ml}$. Figures are means $\pm \mathrm{SD}$. Day 1 is the day of hospitalization.

vasodilation in cerebral arterioles, an effect thought to be mediated by a cGMP-dependent mechanism [17].

Previous studies have shown that CNP is the primary biologically active natriuretic peptide in the brain [18]. CNPlike immunoactivity was detected in human brain, particularly in the thalamus, hypothalamus, and midbrain [19], and its levels were 10-fold those of ANP and BNP.

On the basis of these findings, we assumed that CNP in CSF might have the role of a vasodilator in cerebral arteries. In the present study, plasma CNP levels did not change during the monitoring period; this was in agreement with the report of Eelco et al [20] who showed that plasma ANP and BNP levels increased after SAH, whereas plasma CNP and endothelium CNP were independent of ANP and BNP and did not change very much. We also compared the data with regard to the severity of the spasm and the outcome but found no correlation.

From our findings, we can say that CNP concentration in the CSF was high in the acute phase and decreased gradually after $\mathrm{SAH}$, whereas CNP in the plasma did not change. However, we could not clarify the mechanism of this phenomenon.

\section{References}

1. Toshida K, Nakamura S, Watanabe H: Changes in coagulation fibriolysis and cytokines of patients with subarachnoid hemorrhage. In Proceedings of the 13th Spasm Symposium; Kyoto. Edited by Mamio K. Tokyo: Tyuugaiigaku Co., 1997:243-247. 
2. Otsuka K, Suzuki Y, Takayasu M, Shibuya M, Yoshida J, Yamamoto N, Takahashi N: Changes of cytokine levels in subarachnoid hemorrhage and effect of cytokine on carine basilar artery. In Proceedings of the 12th Spasm Symposium; Kyoto. Edited by Saito I. Tokyo: Tyuugaiigaku Co.; 1996: 234-237.

3. Suzuki M, Endo S, Inada K, Kudo A, Miura K, Kubo N, Kuroda K, Ogawa A: Increased levels of nitrite/ nitrate in the cerebrospinal fluid of patients with subarachnoid hemorrhage. In Proceedings of the 12th Spasm Symposium; Kyoto. Edited by Saito I. Tokyo: Tyuugaiigaku Co; 1996:234-238.

4. Suzuki Y: NO and cerebral vasospasm after subarachnoid hemorrhage. Clin Neurosci 1998, 16:87-89.

5. 5. Komatsu Y, Nakao K, Suga S, Ogawa Y, Mukoyama M, Arai H : C-type natriuretic peptide in rats and humans. Endocrinology 1991, 129:1104-1106.

6. Barr CS, Rhodes P, Struthers AD: C-type natriuretic peptide. Peptides 1996, 17:1243-1251.

7. Neal F Kasseli, Gregory Helm, Nathan Simmons,Douglas P, Cail S: Treatment of cerebral vasospasm with intra arterial papaverine. J Neurosurg 1992, 77:848-852.

8. Hama N, Ito S, Nama N, Itoh H, Shirakawa S, Komatsu Y, Yoshimasu T, Tanaka I, Mori K. Nakao K: Detection of C-type Natriuretic Peptide in human circulation and marked increase of plasma CNP level in septic shock patient. Biochem Biophys Res Comm 1994, 198:1177-1182.

9. Davidson NC, Barr CS, Struthers AD: C-type natriuretic peptide. Circulation 1996, 93:1155-1159.

10. Cargill RI, Struthers AD, Lipworth BJ: Human C-type natriuretic peptide, effect on the hemodynamic and endocrine responses to angiotensin II. Cardiovasc Res 1995, 29:108-111.

11. Barletta G, Lazzeri C, Vecchirino S, Delbene R, Messeri G, Shara $D$, Mannedi M: Low dose C-type natriuretic peptide does not affect cardiac and renal function in humans. Hypertension 1998, 31:802-808.

12. Zhang LM, Castresana MR, McDonald MH, Johnson J, Newman W: Responses of human artery, vein, and cultured smooth muscle cells to atrial and C-type natriuretic peptides. Crit Care Med 1996, 24:306-313.

13. Burnett JC Jr: Coronary endothelial function in health and disease. Drugs 1997, 53 (suppl):s22-s29.

14. Suga $S$, Ito H, Komatsu $Y$, Ogawa $Y$, Name N, Yoshimasa T, Nakao K: Cytokine induced CNP secretion from vascular endothelial cells. Endocrinology 1993, 133:3038-3041.

15. Suzuki Y, Otsuka K, Noda A, Tanazawa T, Takayasu M, Shibuya M, Yoshida J: Nitric oxide metabolism in the cisternal cerebral spinal fluid of the patients with subarachinoid hemorrhage. Neurosurgery 1997, 41:807-812.

16. Mori Y, Takayasu M, Suzuki Y, Shibuya M, Yoshida J, Hidaka H: Vasodilator effects of C-type natriuric peptide on cerebral arterioles in rat. Eur J Pharmacol 1997, 320:183-186.

17. Ogawa $Y$, Nakao K, Nakagawa O, Komatsu $Y$, Hosoda K, Suga $S$, Arai H, Nagata K, Yoshida N, Imura H: Human C-type natriuretic peptide. Hypertension 1992, 19:809-813.

18. Herman JP, Dolgas CM, Marcinek R: Expression and glucocorticoid regulation of natriuretic peptide clearance receptor (NPR-C) mRNA in rat brain and choroid-plexus. J Chem Neuroanat 1996, 11:257-265.

19. Herman JP, Dolgas CM, Rucker D: Localization of natriuretic peptide activated guanylate cyclase mRNAs in the rat brain. $J$ Comp Neurol 1996, 369:165-187.

20. Eelco FM, Schienvik WI, Burnett JC Jr: Natriuretic peptide system and endothelium in aneurysmal subarachnoid hemorrhage. J Neurosurg 1997, 87:275-280. 